\title{
What should we call the 'crista'?
}

\author{
ROBERT H. ANDERSON,1 ANTON E. BECKER, AND \\ LODEWYK H. S. VAN MIEROP \\ From the Department of Paediatrics, Cardiothoracic Institute, Brompton Hospital, London, U.K.; \\ Department of Pathology, University of Amsterdam, Wilhelmina Gasthuis, Amsterdam, The Netherlands; \\ Division of Paediatric Cardiology, $\mathcal{F}$. Hillis Miller Health Center, University of Florida, Gainesville, Florida \\ 32610, U.S.A.
}

Review of published work concerning congenital cardiac anomalies reveals that at least four different structures have been described as the crista supraventricularis, in addition to the structure which in the normally formed right ventricle separates pulmonary and tricuspid valves. Possibility of further confusion arises since at least two different structures have been described under the name 'septal band'. We suggest that this potentially confusing situation will be best resolved by reserving the term 'crista' for description of the muscle mass between inflow and outflow portions of the right ventricle when there are no additional outflow tract anomalies. We then suggest that at least three separate structures warrant description in hearts with outflow tract anomalies. The first separates the semilunar valves, the second separates a semilunar valve from an atrioventricular valve, and the third is an extensive septal trabeculation of the right ventricle. Our suggested terms for these structures are the infundibular septum, ventriculo-infundibular fold, and trabecula septomarginalis, respectively. However, we believe that such terms would be better decided and agreed upon within an internationally formulated 'Nomina Cardiologica', a terminology as yet lacking in congenital heart disease.

Many of the controversies in paediatric cardiology relate not so much to differing observations as to differing interpretations of the embryological derivation of structures, and hence to usage of different names to describe these structures. 'Crista supraventricularis' is among the most abused of such names. Introduced by Wolff (1781) to describe the structure which separates pulmonary and tricuspid valves in the normal right ventricle, the term 'crista' has been applied to at least four different muscular structures related to the outflow tracts of congenitally malformed hearts (Fig. 1). The confusion produced by such usage is compounded by the fact that other terms have been used to describe these structures by other investigators, and in several instances the same name has been applied to different structures by different workers. Our present purpose is to make a plea for uniformity, and thus attempt to avoid such differences in usage by future workers who study congenitally malformed hearts. We accept that achievement of such uniformity will be difficult if not impossible. None the less, we suggest that the first step in achieving such uniformity will be the reservation ${ }^{1}$ RHA is a British Heart Foundation Senior Research Fellow.

Received for publication 9 February 1977 of the term 'crista' for description of the supraventricular muscle mass of the normal right ventricle, as indeed it was initially intended. We have previously argued at length why we believe this to be necessary (Becker et al., 1975; Shinebourne et al., 1975), and similar arguments have been advanced by Goor and Lillehei (1975). If 'crista' is discarded in other contexts, we believe the next essential step will be to define any structures worthy of description in anatomical terms alone, without reference to embryological interpretation.

In our opinion, in all hearts with malformations of the outflow tracts, at least three muscular structures always warrant definition and description. The first is a muscle bundle which, in anatomical terms, separates the two semilunar valves, whatever the ventricular origin of these valves. The second is, again in anatomical terms, a muscular structure which separates a semilunar from an atrioventricular valve, whether these valves are in the morphologically right or left ventricles or in a primitive (single) ventricle. The third and final structure is a prominent septal trabeculation which is one of the anatomical features of the morphologically right ventricle. It can rightly be argued that when defined in such terms it matters little what the structures 
2.

Part of cristo (Rosenquist et 01,1973 ) Porietal band II (Lev et al., 1972)

Bulbootrioventricular ledge (Anderson et al,1974a) Conoventricular flonge (Becker et ol,1975) Conal free wall (Von Proogh, 1965)

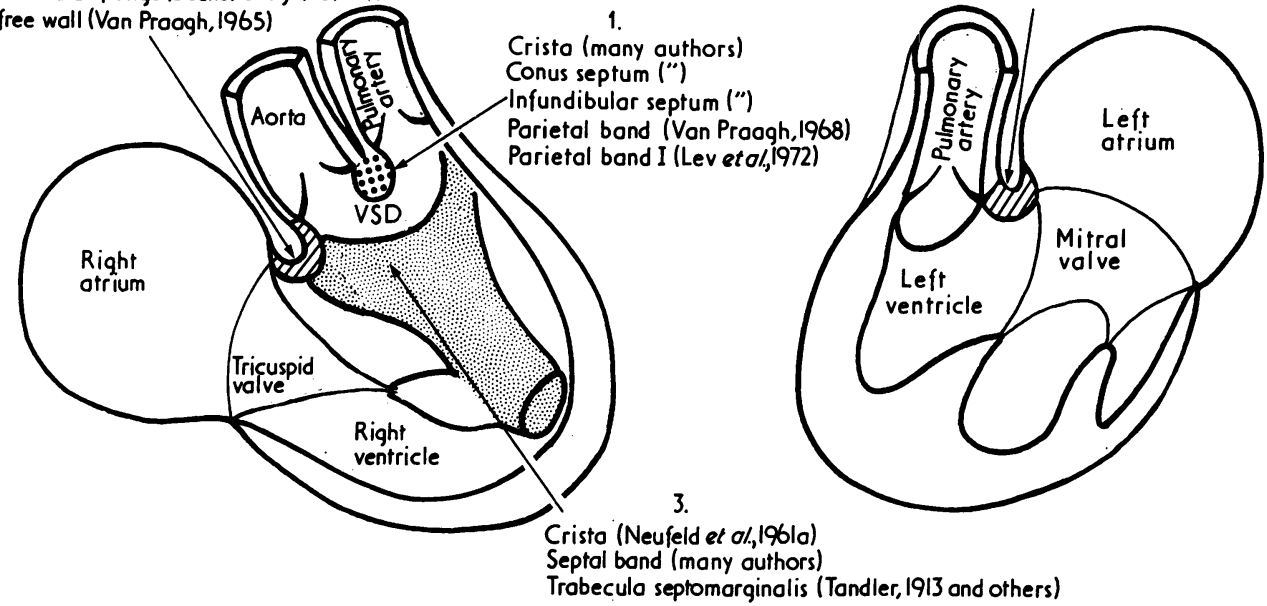

Fig. 1 Diagrammatic representation of hypothetical hearts to illustrate the structures which, by different investigators at different times, have been termed the crista supraventricularis, or described as part of the 'crista'. The diagram on the left illustrates a hypothetical double outlet right ventricle. The ventricular septal defect is shown beneath both semilunar valves, since it bears a similar relation to whichever great artery is above it. The diagram on the right illustrates a hypothetical case of overriding pulmonary artery with muscular tissue between the pulmonary and mitral valves. The references are chosen only as illustrative examples, and are in no way to be construed as an exhaustive catalogue or as indicating precedence of description.

are called, since if each investigator carefully defines his terms, all will be able to comprehend his nomenclature. However, we contend that it is self evident that uniformity of nomenclature of anatomical structures in normal and anomalous postnatal hearts will considerably facilitate both mutual understanding and communication.

If such a uniform nomenclature is to satisfy our second suggested criterion and eschew embryological considerations, we submit it must not use the term 'conus' (Van Mierop, 1974). For this reason, some of us are forced to change our nomenclature, which has hitherto employed the term 'conus' extensively (Becker et al., 1975; Shinebourne et al., 1975). It can be argued that nomenclature should be changed only if the previous nomenclature is either inaccurate or unsatisfactory. We submit that this is indeed the case with 'conus'. The term is used to describe different parts of the embryonic heart by different investigators (Goor and Lillenhei, 1975). As used by Goor and Lillehei (1975), the 'conus' seems to be interchangeable with the time-honoured 'infundibulum', as is indeed indicated by these authors. However, Goor (1972) had earlier reacted strongly against a suggestion by Lev (1972) that 'infundibulum' be sub- stituted for 'conus'. In contrast to this usage, Van Praagh and Van Praagh (1965) specifically argued that the 'conus' was not to be considered as a cylinder of musculature (p. 420). Further difficulties arise from usage of 'conus' which derive from embryological interpretations. Goor and Lillehei (1975) argued that the embryonic conus septum became infiltrated by musculature in the normal heart, and formed the entirety of the normal crista supraventricularis. This is in contrast to our own observations (Anderson et al., 1974a, b; Van Mierop, 1974). Furthermore, they argued that in truncus specimens, a ridge of tissue adjacent to the atrioventricular valve was a remnant of the conus septum, while agreeing with the concept of Van Praagh and Van Praagh (1965) that truncus hearts with tricuspid semilunar valves resulted from lack of growth of the subpulmonary conus. This seems an inconsistent argument and underlines the necessity for our second requirement, that of avoiding embryological interpretations when naming structures in anomalous hearts. From these considerations it follows that the term 'conus' must be discarded in descriptions of postnatal, or fully developed hearts. We further suggest that Lev's (1972) advice be followed, and the term 'infundibulum' be substi- 
tuted for 'conus', as in the recent study of English (1976). This use of 'infundibulum' makes it easy to name the first two of the three structures described above. Thus, the structure which interposes between two semilunar valves can be described as the infundibular septum (Fig. 2). In malformed hearts this septum usually has a body, a septal insertion, and a parietal insertion. Any muscular structure which in an anomalous heart separates the semilunar from the atrioventricular valves can be termed the ventriculo-infundibular fold (Fig. 2). This term is applicable whether the fold exists in a right, a left, or a primitive ventricle. If this fold is attenuated, then fibrous continuity will exist between semilunar and atrioventricular valves. Though the structure frequently appears as a bar of muscle, transection in a specimen will show that it is a reduplication of the inner curve of the heart wall (Becker et al., 1975). For this reason, 'fold' is a better term than 'flange'.

Naming of the third structure defined above is not made any easier by usage of 'infundibulum'. This is an extensive septal trabeculation seen only in the morphologically right ventricle; it both reinforces the anteroinferior border of many septal defects and supports the tricuspid valve via the medial and anterior papillary muscles which arise directly from the trabecula. The term 'septal band' is widely applied to this structure and has good pedigree (Keith, 1909). However, confusion can arise in clinical usage between the 'septal band' as thus defined and the septal insertion of the infundibular septum, which was termed the 'septal band' by Kjellberg et al. (1959) in hearts with Fallot's tetralogy. It is for this reason that we prefer the term trabecula septomarginalis for the former (Van Mierop et al., 1963; Becker et al., 1975; Shinebourne et al., 1975). We accept that this term as used by anatomists describes only the moderator band (International Anatomical Nomenclature Committee, 1966). None the less, Tandler (1913) described how, in occasional normal specimens, the trabecular structure could be identified running up towards the crista, and in such normal hearts used 'trabecula septomarginalis' to describe the entire complex. We believe that this occurrence is the rule rather than the exception, and therefore use the term 'trabecula septomarginalis', believing it to be more explicit and less confusing than 'septal band'.

Thus, in conclusion, we submit that the term 'crista supraventricularis' should be used only in the description of hearts with normal right ventricular outflow tracts, without anomalies which derange the alignment of the outflow musculature. Ideally, any substituted nomenclature for description of the supraventricular structures existing in malformed hearts should be agreed in an International document similar to the Nomina Anatomica.

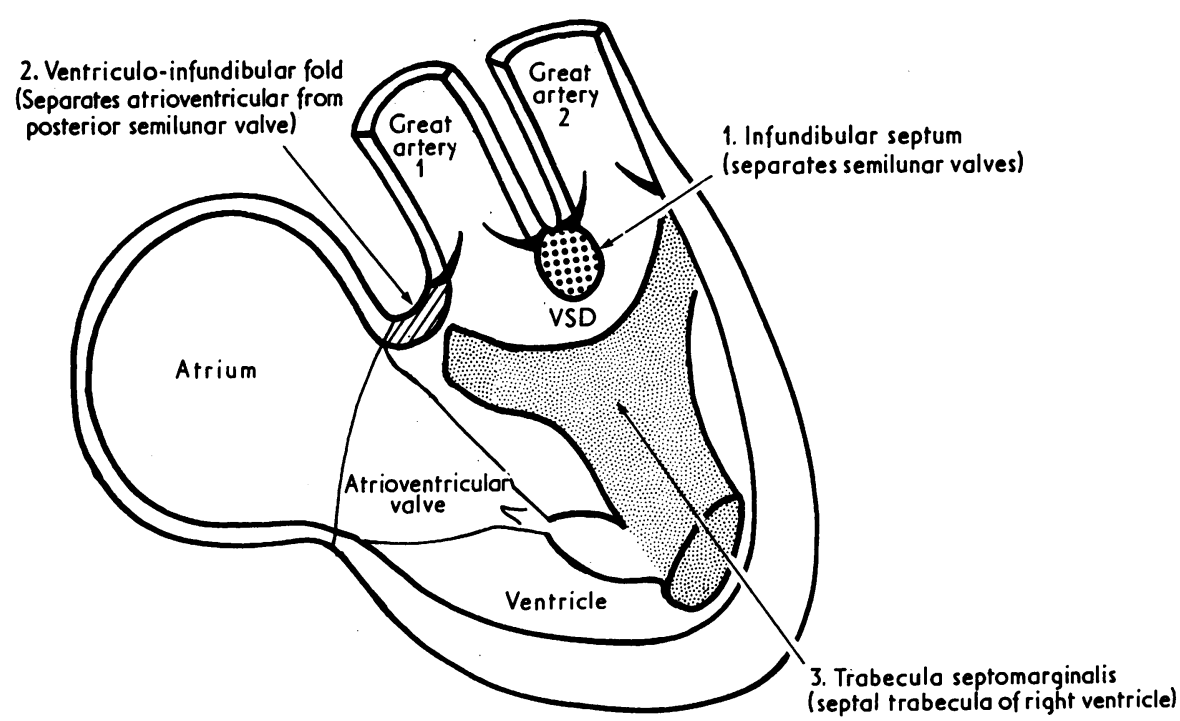

Fig. 2 Diagrammatic representation of suggested terms of muscular structures herein defined. Definitions of structures 1 and 2 are applicable whichever ventricle supports the valve or valves. The structures are illustrated in a diagrammatic right ventricle, however, since structure 3 is one of the distinguishing morphological features of the right ventricle. 
Until such a 'Nomina Cardiologica' is formulated, we suggest that any structure requiring description is first defined and then named using anatomical terms, avoiding all interpretations of supposed embryology. We have proposed our own terms using such criteria and present them in the hope that they will stimulate discussion and lead to the formulation of a 'Nomina Cardiologica'.

\section{References}

Anderson, R. H., Wilkinson, J. L., Arnold, R., and Lubkiewicz, K. (1974a). Morphogenesis of bulboventricular malformations. I. Consideration of embryogenesis in the normal heart. British Heart fournal, 36, 242-255.

Anderson, R. H., Wilkinson, J. L., Arnold, R., Becker, A. E. and Lubkiewicz, K. (1974b). Morphogenesis of bulboventricular malformations. II. Observations on malformed hearts. British Heart fournal, 36, 948-970.

Becker, A. E., Connor, M., and Anderson, R. H. (1975). Tetralogy of Fallot. A morphometric and geometric study. American fournal of Cardiology, 35, 402-412.

English, T. A. H. (1976). The outflow tract and pulmonary arteries in Fallot's tetralogy and pulmonary atresia with ventricular septal defect. In Surgery of the Heart, p. 85. Ed. by J. A. Dyde and R. E. Smith. Plenum, New York.

Goor, D. A. (1972). The conotruncus: I. Its normal inversion and conus absorption. (Correspondence.) Circulation, 46, 635.

Goor, D. A., and Lillehei, C. W. (1975). Congenital Malformations of the Heart. Embryology, Anatomy and Operative Considerations. Grune and Stratton, New York.

International Anatomical Nomenclature Committee (1966). Nomina Anatomica, 3rd ed. Excerpta Medica, Amsterdam.

Keith, A. (1909). The Hunterian Lectures on malformations of the heart. Lancet, 2, 359-363, 433-435, and 519-523.

Kjellberg, S. R., Mannheimer, E., Rudhe, U., and Jonsson, B. (1959). Diagnosis of Congenital Heart Disease, 2nd ed. Year Book Medical Publishers, Chicago.

Lev, M. (1972). The conotruncus: I. Its normal inversion and conus absorption. (Correspondence.) Circulation, 46, 634-635.
Lev, M., Bharati, S., Meng, C. C. L., Liberthson, R. R., Paul, M. H., and Idriss, F. (1972). A concept of double outlet right ventricle. Fournal of Thoracic and Cardiovascular Surgery, 64, 271-281.

Neufeld, H. N., DuShane, J. W., and Edwards, J. E. (1961a). Origin of both great vessels from the right ventricle. II. With pulmonary stenosis. Circulation, 23, 603-612.

Neufeld, H. N., DuShane, J. W., Wood, E. H., Kirklin, J. W., and Edwards, J. E. (1961b). Origin of both great vessels from the right ventricle. I. Without pulmonary stenosis. Circulation, 23, 399-412.

Rosenquist, G. C., Sweeney, L. J., Stemple, D. R., Christianson, S. D., and Rowe, R. D. (1973). Ventricular septal defect in tetralogy of Fallot. American fournal of Cardiology, 31, 749-754.

Shinebourne, E. A., Anderson, R. H., and Bowyer, J. J. (1975). Variations in clinical presentation of Fallot's tetralogy in infancy-angiographic and pathogenetic implications. British Heart fournal, 37, 946-955.

Tandler, J. (1913). Anatomie des Herzens, p. 64. Gustav Fischer, Jena.

Van Mierop, L. H. S. (1974). Anatomy and embryology of the right ventricle. In The Heart, pp. 1-16. Ed. by J. E. Edwards, M. Lev, and M. R. Abell. Williams and Wilkins, Baltimore.

Van Mierop, L. H. S., Alley, R. D., Kausel, H. W., and Stranahan, A. (1963). Pathogenesis of transposition complexes. I. Embryology of the ventricles and great arteries. American fournal of Cardiology, 12, 216-225.

Van Praagh, R. (1968). What is the Taussig-Bing malformation? Circulation, 38, 445-449.

Van Praagh, R., and Van Praagh, S. (1965). The anatomy of common aorticopulmonary trunk (truncus arteriosus communis) and its embryologic implications. American Fournal of Cardiology, 16, 406-425.

Wolff, C. F. (1781). Acta Academiae Scientiarum Imperialis Petropolitanae. (Cited by Tandler, 1913.)

Requests for reprints to Dr. R. H. Anderson, Department of Paediatrics, Cardiothoracic Institute, Brompton Hospital, Fulham Road, London SW3 6HP. 